The Egyptian Journal of Hospital Medicine (April 2019) Vol. 75 (5), Page 2913-2920

\title{
Factors Influencing Surgical Outcome of Intermittent Exotropia
}

\author{
Hanan S. Hegazy
}

Department of Ophthalmology, Faculty of Medicine (for Girls), Al-Azhar University, Cairo, Egypt.

Corresponding author: Hanan S. Hegazy, Tel: +002 01013755550, e-mail: hanansaied27@yahoo.com

\begin{abstract}
Purpose: The purpose of this study was to analyze the factors affecting surgical results of intermittent exotropia.

Methods: A prospective interventional study included patients with basic type of intermittent exotropia who had undergone surgical treatment with a postoperative follow up period of 1 month or more. Surgical success was defined as an alignment between 10 prism diopters (PD) of exotropia or $10 \mathrm{PD}$ of esotropia at 1 month. The factors investigated were: sex, age of patients, and age at initial surgery, family history, preoperative angle of deviation, type of surgery, the tendon width of lateral rectus muscle, refractive error, near binocular single vision, and postoperative alignment. After data collection, data were analyzed in SPSS version 25 software.

Results: The study included 26 patients, 13 (50\%) male and 13 (50\%) female followed up for 3 months. All of patients achieved surgical success but patients with larger preoperative angle of deviation, older age and larger tendon muscle width showed exotropia with in (10PD) which showed slight improvement during period of follow up while those with smaller preoperative angle, younger age and smaller tendon muscle width showed esotropia with in (10) PD and associated with postoperative diplopia relieved during period of follow up with improvement of esotropia.

Conclusion: In intermittent exotropia, age, tendon width, preoperative angle of deviation may predict the surgical success rate. Younger age, smaller preoperative angle, smaller tendon muscle width, early postoperative small angle esotropia were associated with a higher surgical success.
\end{abstract}

Keywords: Intermittent exotropia, surgical outcome, tendon muscle width.

\section{INTRODUCTION}

Intermittent exotropia $\mathrm{X}(\mathrm{T})$ is considered the most common form of exotropia and is more prevalent among Asians $^{(1)}$. It comprises about $50 \%$ to $90 \%$ of patients with exodeviation $^{(2)}$. $\mathrm{X}(\mathrm{T})$ was defined as a divergent deviation intermittently controlled by fusional mechanisms ${ }^{(3)}$. X(T) can be treated through nonsurgical methods which aim to encourage use of the eyes together by eliminating suppression and building fusional reserves (motor control of the eyes) in order to aid control of the exodeviation. They include exercises, parttime occlusion or minus lens therapy ${ }^{(4)}$.

Surgery is mainly used to treat $\mathrm{X}(\mathrm{T})$ with a satisfactory outcome ${ }^{(5)}$. The commonly used surgical methods for $\mathrm{X}(\mathrm{T})$ include bilateral lateral rectus recession (BLR), unilateral lateral rectus recession and medial rectus resection $(R \& R)$ or unilateral lateral rectus recession (ULR) which is often used to treat small to moderate angle exotropia ${ }^{(2)}$.

The success was considered when rate in terms of ocular motor alignment of within 10 prism diopters (PD) of orthotropia ${ }^{(6,7)}$.

Additional surgery may be needed for cases with under correction. Many studies have found that longterm post-operative alignment is better when there is over-correction in the very early period following surgical procedures so, the usual goal of surgery for intermittent exotropia is a small angle of initial postoperative esodeviation. Because small esodeviation typically recovers to orthophoria within 2 weeks without any manipulations ${ }^{(8)}$.

VonNoorden $^{(9)}$ found that lesser degrees of overcorrection were associated with recurrence of exodeviation and that higher degrees of overcorrection increased the risk of reoperation for consecutive esotropia. Raab and Parks ${ }^{(10)}$ reported that initial (2-10 days) postoperative alignment between 11 and 20PD esodeviation remained satisfactory.

Whereas Scott ${ }^{(11)}$ proposed the surgical goals of 4-14 PD esodeviation, and $\mathbf{M c N e e r}^{(12)}$ of 0-10 PD. There are multiple factors that may affect prognosis of surgery for $X(T)$. Preoperative factors include age at onset of $X(T)$, age at time of surgery, preoperative degree of exodeviation, stereopsis, refractive errors, amblyopia, inferior oblique muscle overaction, and type of exotropia $^{(13)}$. .

Operative factors include surgical procedure, the limbal insertion distance (LID) of the LR muscle as undercorrection at the time of LR recession might be considered in patients with long LID of the LR muscle ${ }^{(14)}$.

The tendon width of the lateral rectus also has been reported to be a useful indicator for estimation of the effect of lateral rectus recession in $\mathrm{X}(\mathrm{T})$. The mean effect of $1 \mathrm{~mm}$ lateral rectus recession has been shown to range from 2.7 to $3.5(\mathrm{PD})^{(15)}$. According to tendon width, the effect of recession has been shown to be larger in cases in which the lateral rectus tendon width is narrower. That 
is because the tendon width might speak for muscle hypertrophy or contracture from increased innervation on the lateral rectus muscles in exotropia ${ }^{(15)}$.

The actual dose response effect is calculated by finding the difference between preoperative and postoperative angle deviation and then dividing the result by the total amount of recession at postoperative month 1 and $3^{(14)}$. Postoperative factor is the degree of postoperative ocular alignment

\section{PATIENTS AND METHODS}

A prospective interventional study was carried out at Al-Zahraa University Hospital from September 2017 to November 2018 and included 26 patients with basic type of intermittent exotropia $\mathrm{X}(\mathrm{T})$. The study adhered to the tenets of the Declaration of Helsinki and was approved by the ethics board of Al-Azhar University and an informed written consent was taken from each participant in the study and from the parents in young children.

Patients were divided according to age into two groups. Group (1) 13 patients ranging in age from 4 to 10 years. Group (2) 13 patients over 10 years of age, all of whom were diagnosed with $\mathrm{X}(\mathrm{T})$ and in need of surgical treatment. Patients also were divided into three groups according to preoperative refractive error: those with spherical equivalent in both eyes $\geq+1 \mathrm{D}$ were classified as group I (hyperopic $\mathrm{X}(\mathrm{T})$ group), patients with spherical equivalent of both eyes between $-1 \mathrm{D}$ and $+1 \mathrm{D}$ were classified as group II (emmetropic $\mathrm{X}(\mathrm{T})$ group), and patients with spherical equivalent of both eyes $\leq-1 \mathrm{D}$ were classified as group III (myopic X(T) group).

According to intraoperative measurement of tendon width patients were divided into three groups: Group A $(8 \mathrm{~mm})$, group B $(8.5-9 \mathrm{~mm})$, group c $(9.5 \mathrm{~mm})$.

Measurements of the angle of deviation with and without glasses were obtained in all patients at distance $(6 \mathrm{~m})$ and near $(33 \mathrm{~cm})$ primary positions with fixation on accommodative targets. Measurements were taken after 1 hour of monocular occlusion of the non-dominant eye if the distant angle of exodeviation was 10 PD more than the near angle to differentiate true from simulated divergence excess. Cycloplegic refraction was performed using $1 \%$ cyclopentolate eye drops 3 times at 5 -minute intervals. Sensory function was evaluated using the Titmus and the Worth 4-dot test.

Patients were excluded from the study if they have amblyopia, large angle exotropia that necessitates three muscle surgery, constant exotropia or intermittent exotropia with poor Newcastle score $\geq 7$, consecutive exotropia, recurrent exotropia, restrictive strabismus, lateral incomitance, presence of $\mathrm{AV}$ pattern or inferior oblique overaction.

Surgery was considered if there was increase of the tropia phase of the intermittent exotropia or the angle of deviation measures at least15 PD. All patients got the surgery with a NCS score of 3 or more. All of the surgeries were performed under general anesthesia using the standard limbal approach by one surgeon at $\mathrm{Al}$ zahraa university hospital. Unilateral or bilateral rectus muscle recession is done according to the preoperative angle of deviation.

In the current study the desirable surgical outcome was initial overcorrection protocol. Park's surgical dose table was followed for group (1) below 10 years without modification of the surgical dose but in group (2) more than 10 years old. The dose of LR recession was increased to the amount needed to correct a preoperative angle that was 5 PD larger than the real angle ${ }^{(16)}$.

The tendon width of the lateral rectus muscle was measured in all patients using a caliber before muscle disinsertion. The angle of deviation measured within a week of surgery was defined as the immediate postoperative deviation. Follow-up visits were scheduled at $1^{\text {st }}$ day, $1^{\text {st }}$ week, $1^{\text {st }}$ month and $3^{\text {rd }}$ month postoperatively.

Surgical outcomes and factors for analysis of significance were based on gender, the patient's age at surgery, preoperative angle of deviation, spherical equivalent (SE) refractive error, tendon width as well as postoperative alignment in the follow up visits.

Analysis of data was performed using SPSS v. 25 (Statistical Package for Scientific Studies) for Windows $\&$ MedCalc v. 18. Data were explored for normality using Kolmogorov-Smirnov test of normality. The results of Kolmogorov-Smirnov test indicated that most of data were normally distributed (parametric data) so parametric tests were used for most of the comparisons. A p-value $\leq 0.05$ was regarded as statistically significant.

\section{RESULTS}

26 patients were included in this study. 13 were males (age range from 4-31) and 13 were females (age range from 7-38) patients (tables $1 \& 2$ ). 14 of the patients $(53.8 \%)$ had a family history of strabismus (table 3 ). The mean \pm SD of preoperative angle of deviation was 33.84 \pm 8.52 PD (range, 20-45 PD). Patients were classified according to refractive errors into 3 groups, 3 (11.5\%) were myopic (spherical equivalent $<$ or $=-1.00$ diopters); 4 (15.4\%) were hyperopic spherical equivalent $>$ or $=-1.00$ diopters); 19 (73.1\%) were emmetropic (spherical equivalent diopter: within \pm 1.00 diopters) (table 4). Only 18 patients had documented Titmus stereo test results, $14(77.8 \%)$ patients were classified as 
having good stereoacuity, 4 (22.2\%) as having moderate stereoacuity (table 5 , figure 1 ).

Table 1: Gender distribution in the study group ( $\mathrm{n}=26$ cases)

\begin{tabular}{|c|c|c|}
\hline Gender & Male & Female \\
\hline No. & 13 & 13 \\
\hline$\%$ & 50 & 50 \\
\hline
\end{tabular}

Table 2: Age distribution in the study group $(n=26$ cases)

\begin{tabular}{|c|l|l|l|}
\hline Age (y) & Mean & SD & Range \\
\hline Male & 11.692 & 7.3074 & $4-31$ \\
\hline Female & 15.077 & 9.6563 & $7-38$ \\
\hline All & 13.385 & 8.5654 & $4-38$ \\
\hline
\end{tabular}

Table 3: Family history of intermittent exotropia(X(T) in the study group

\begin{tabular}{|c|c|c|}
\hline Family history of X(T) & No.(26) & \% \\
\hline Yes & 14 & 53.8 \\
\hline No & 12 & 46.2 \\
\hline
\end{tabular}

Table 4: Distribution of spherical equivalent of both eyes in the study group

\begin{tabular}{|l|c|c|}
\hline \multicolumn{1}{|c|}{ spherical equivalent } & No.(26) & \% \\
\hline$\geq 1 \mathrm{D}$ & 4 & 15.4 \\
\hline$\leq-1 \mathrm{D}$ & 3 & 11.5 \\
\hline 1 to $-1 \mathrm{D}$ & 19 & 73.1 \\
\hline
\end{tabular}

Table 5: Distribution of stereoacuityin the study group ( $\mathrm{n}=18$ cases)

\begin{tabular}{|l|c|c|}
\hline Stereoacuity & No. & \% \\
\hline$\leq 100$ & 14 & 77.8 \\
\hline$>100$ & 4 & 22.2 \\
\hline
\end{tabular}

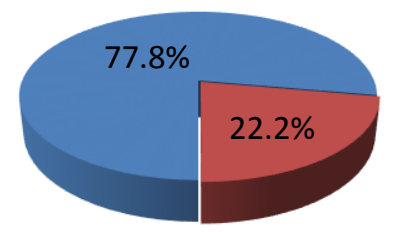

\section{Steroacuity $\leq 100 \square>100$}

Figure 1: Distribution of stereoacuity in the study group $(n=18$ cases $)$

Across all patients, 5 patients $(19.1 \%)$ received onemuscle surgery, 21 patients $(80.8 \%)$ received bilateral lateral rectus recession. The mean age for surgery was 13.385 years (table 6).

Table 6: Distribution of recession laterality in the study group ( $\mathrm{n}=26$ cases)

\begin{tabular}{|l|c|c|}
\hline Recession laterality & No. & \% \\
\hline Bilateral & 21 & 80.8 \\
\hline Unilateral & 5 & 19.1 \\
\hline
\end{tabular}

The patients were divided into two groups; Group (1) 13 patients who were younger than 10 years old with mean preoperative angle $34.23 \pm 5.71$ and mean postoperative angle was $-6.76 \pm 4.04$ with minus sign for esotropia.

Group (2) 13 patients who were older than 10 years old the preoperative angle was $33.46 \pm 10.87$ and mean postoperative angle was $+7.23 \pm 2.08$ with + sign for exotropia. There is improvement of both groups with statistically significant decrease of mean postoperative angle in group 1 in comparison to postoperative postoperative angle of group $2(\mathrm{P} .<0.05)$ (table 7$)$.

Table 7: Comparison between age groups according to pre and postoperative angle by ANOVA test

\begin{tabular}{|c|l|l|l|l|l|}
\hline \multirow{2}{*}{ Angle $(\mathrm{PD})$} & \multicolumn{2}{|c|}{$\begin{array}{c}\text { Group 1 }(\leq 10 \mathrm{y})(13 \\
\text { patients })\end{array}$} & \multicolumn{2}{c|}{$\begin{array}{c}\text { Group 2 }(>10 \mathrm{y}) \\
(13 \text { patients })\end{array}$} & \multirow{2}{*}{ P.value } \\
\cline { 2 - 6 } & Mean & SD & Mean & SD & \\
\hline Preoperative angle & 34.23 & 5.71 & 33.46 & 10.87 & 0.823 \\
\hline Postoperative angle & -6.76 & 4.04 & +7.23 & 2.08 & $<0.001$ \\
\hline
\end{tabular}

(-) means esodeviation. (+) means exodeviation

Comparison between actual and hypothetical effect by ANOVA test revealed that there is statistically insignificant increase of mean actual effect in group 1 in comparison to hypothetical effect (P.> 0.05) and significant decrease of mean actual effect in group 2 in comparison to hypothatical effect $(\mathrm{P} .<0.05)$ (table 8, figure 2). Table (9) showed that there was statistically significant increase of mean actual effect in group 1 in comparison to group 2(P.< $0.05)$. 
Factors Influencing Surgical Outcome of Intermittent Exotropia

Table 8: Comparison between actual and hypothetical effect according to age groups by ANOVA test

\begin{tabular}{|l|l|c|c|c|c|}
\hline \multirow{2}{*}{ Age group } & \multicolumn{2}{|l|}{ Actual effect $(\mathrm{pd} \mathrm{mm})$} & \multicolumn{2}{l|}{ Hypothatical effect $(\mathrm{pd} \mathrm{mm})$} & \multirow{2}{*}{ P.value } \\
\cline { 2 - 6 } & Mean & SD & Mean & SD & \\
\hline Group1 & 2.57 & 0.33 & 2.43 & 0.20 & 0.0860 \\
\hline Group 2 & 1.78 & 0.35 & 2.30 & 0.27 & $<0.0001$ \\
\hline All group & 2.18 & 0.52 & 2.36 & 0.24 & 0.0264 \\
\hline
\end{tabular}

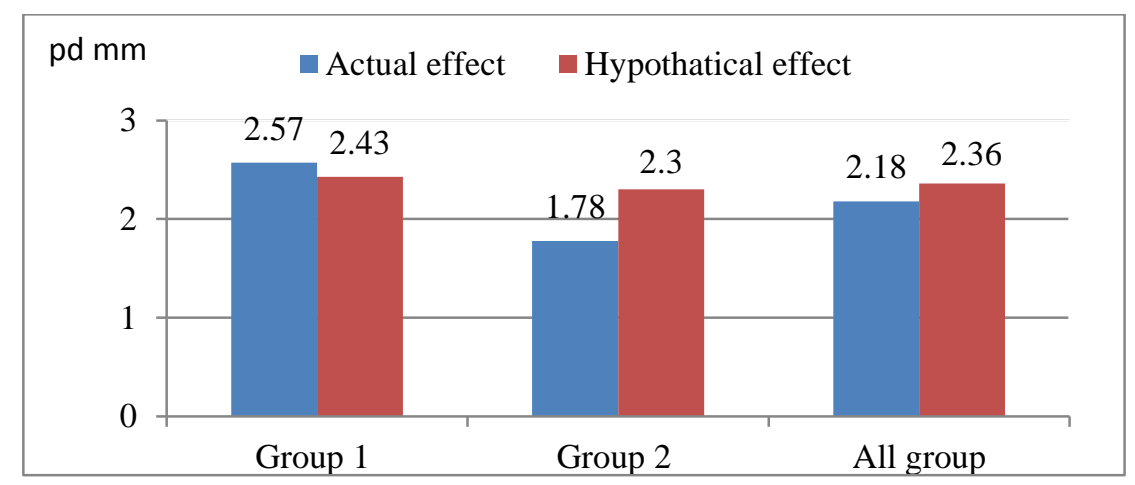

Figure 2: Comparison between actual and hypothetical effect according to age groups by ANOVA test

Table 9: Relation of Actual \&hypothatical effect with age groups by ANOVA test

\begin{tabular}{|l|c|c|c|c|c|}
\hline \multirow{2}{*}{ Effect $(\mathrm{pd} \mathrm{mm})$} & \multicolumn{2}{|c|}{ Group 1 } & \multicolumn{2}{c|}{ Group 2 } & \multirow{2}{*}{ P.value } \\
\cline { 2 - 5 } & Mean & SD & Mean & SD & \\
\hline Actual effect & 2.57 & 0.33 & 1.78 & 0.35 & $<0.001$ \\
\hline Hypothatical effect & 2.43 & 0.20 & 2.30 & 0.27 & 0.206 \\
\hline
\end{tabular}

According to intraoperative measurement of tendon width patients were divided into three groups: Group A $(8 \mathrm{~mm})$ were 5 patients, group B $(8.5-9 \mathrm{~mm})$ were 10 patients and group c $(9.5 \mathrm{~mm})$ were 11 patients. Table (10) shows that there is statistically significant increase of mean actual effect in group A in comparison to hypothetical effect $(\mathrm{P} .<0.05)$ and significant decrease of mean actual effect in group $\mathrm{C}$ in comparison to hypothatical effect $(\mathrm{P} .<0.05)$ (figure 3 ).

Table 10: Comparison between actual and hypothetical effect according to tendon width groups by ANOVA test

\begin{tabular}{|l|c|c|c|c|c|c|}
\hline \multirow{2}{*}{ Tendon width } & \multirow{2}{*}{$\begin{array}{c}\text { Number } \\
\text { (26) }\end{array}$} & \multicolumn{2}{|c|}{ Actual effect $(\mathrm{pd} \mathrm{mm})$} & \multicolumn{2}{c|}{ Hypothetical effect $(\mathrm{pd} \mathrm{mm})$} & \multirow{2}{*}{ P.value } \\
\cline { 3 - 6 } & Mean & SD & Mean & SD & \\
\hline Group A $(8 \mathrm{~mm})$ & 5 & 2.60 & 0.14 & 2.28 & 0.17 & 0.0054 \\
\hline Group B $(8.5-9 \mathrm{~mm})$ & 10 & 2.51 & 0.38 & 2.50 & 0.21 & 0.8905 \\
\hline Group C $(9.5 \mathrm{~mm})$ & 11 & 1.69 & 0.30 & 2.29 & 0.25 & $<0.0001$ \\
\hline
\end{tabular}

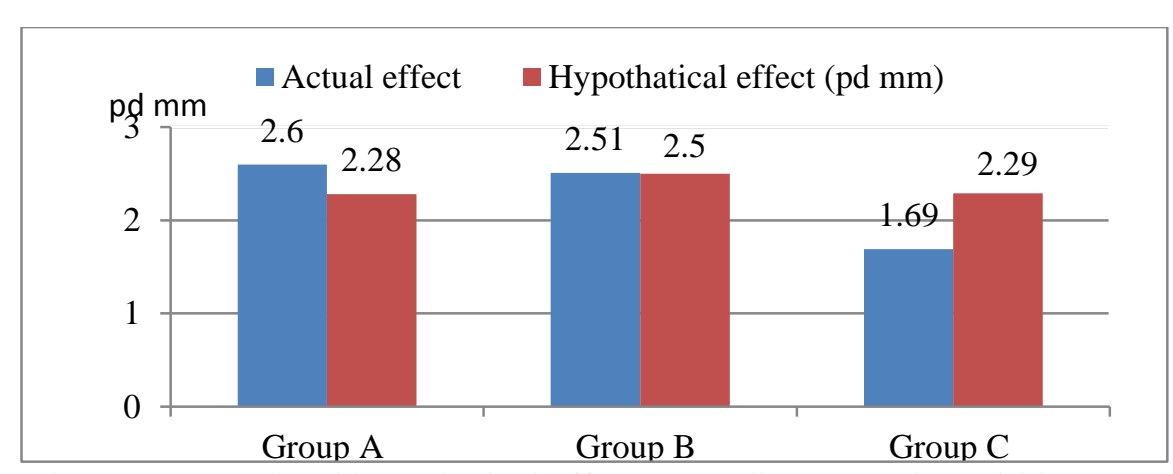

Figure 3: Comparison between actual and hypothetical effect according to tendon width groups by ANOVA test Also relation of actual and hypothatical effect with tendon width groups showed that there is statistically significant difference of mean actual effect between different groups of tendon width (group A, B ,C) (table 11, figure 4). 
Table 11: Relation of Actual \& hypothatical effect with tendon width groups by ANOVA test in the study group

\begin{tabular}{|l|c|c|c|c|c|c|c|}
\hline \multirow{2}{*}{ Effect (pd mm) } & \multicolumn{2}{|c|}{ Group A } & \multicolumn{2}{c|}{ Group B } & \multicolumn{2}{c|}{ Group C } & \multirow{2}{*}{ P.value } \\
\cline { 2 - 8 } & Mean & SD & Mean & SD & Mean & SD & \\
\hline Actual effect & 2.60 & 0.14 & 2.51 & 0.38 & 1.69 & 0.30 & $<0.001$ \\
\hline Hypothatical effect & 2.28 & 0.17 & 2.50 & 0.21 & 2.29 & 0.25 & 0.094 \\
\hline
\end{tabular}

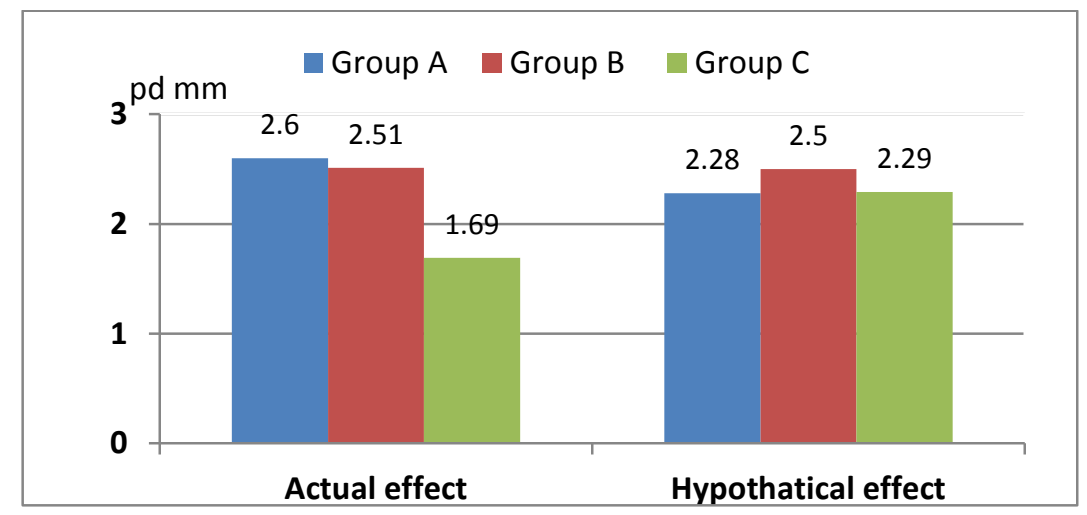

Figure 4: Relation of Actual \&hypothatical effect with tendon width groups by ANOVA test in the study group

According to the postoperative angle, all patients showed surgical success but 12 patients $(46.2 \%)$ showed esodeviation $\pm 10 \mathrm{PD}$ and $14(53.8 \%)$ patients showed exodeviation $\pm 10 \mathrm{PD}$ (table 12$)$

Table 12: Distribution of alignment in the study group according to postoperative angle

\begin{tabular}{|l|c|c|c|c|}
\hline \multirow{2}{*}{ Postoperative angle } & \multicolumn{3}{|c|}{ No.(26) } & \multirow{2}{*}{$\%$} \\
\cline { 2 - 4 } & Male & Female & Total & \\
\hline Esodeviation of $\leq 10 \mathrm{PD}$ & $7(58.3 \%)$ & $5(41.7 \%)$ & 12 & 46.2 \\
\hline Exodeviation of $\leq 10 \mathrm{PD}$ & $6(42.9)$ & $8(57.1)$ & 14 & 53.8 \\
\hline
\end{tabular}

Pearson correlation between actual effect and other variables in the study group showed that there is statistically significant positive correlation between actual effect and preoperative angle in all study group $(\mathrm{r}=0.5294, \mathrm{P} .<0.05)$. Astatistically significant negative correlation between actual effect and age in all study group $(r=-0.7375, P .<0.05)$. There is statistically significant negative correlation between actual effect and NCS in all study group ( $\mathrm{r}=-0.6181$, P. $<0.05)$. There is statistically significant positive correlation between actual effect and recession amount in all study group $(\mathrm{r}=0.7412, \mathrm{P} .<0.05)$. (table 13, figure 5)

Table 13: Pearson correlation between actual effect and other variables in the study group ( $\mathrm{n}=26$ cases).

\begin{tabular}{|l|c|c|}
\hline \multirow{2}{*}{\multicolumn{1}{|c|}{ Variable }} & \multicolumn{2}{c|}{ Actual effect $(\mathrm{pd} \mathrm{mm})$} \\
\cline { 2 - 3 } & Correlation $(\mathbf{r})$ & P.value \\
\hline Age $(\mathrm{y})$ & -0.7375 & $<0.0001$ \\
\hline Pre.op angle $(\mathrm{pd})$ & 0.5294 & 0.0054 \\
\hline NCS(Newcastle score) & -0.6181 & 0.0008 \\
\hline Recession amount $(\mathrm{mm})$ & 0.7412 & $<0.0001$ \\
\hline Sph.Eq of both eyes & 0.09375 & 0.6487 \\
\hline
\end{tabular}


Factors Influencing Surgical Outcome of Intermittent Exotropia
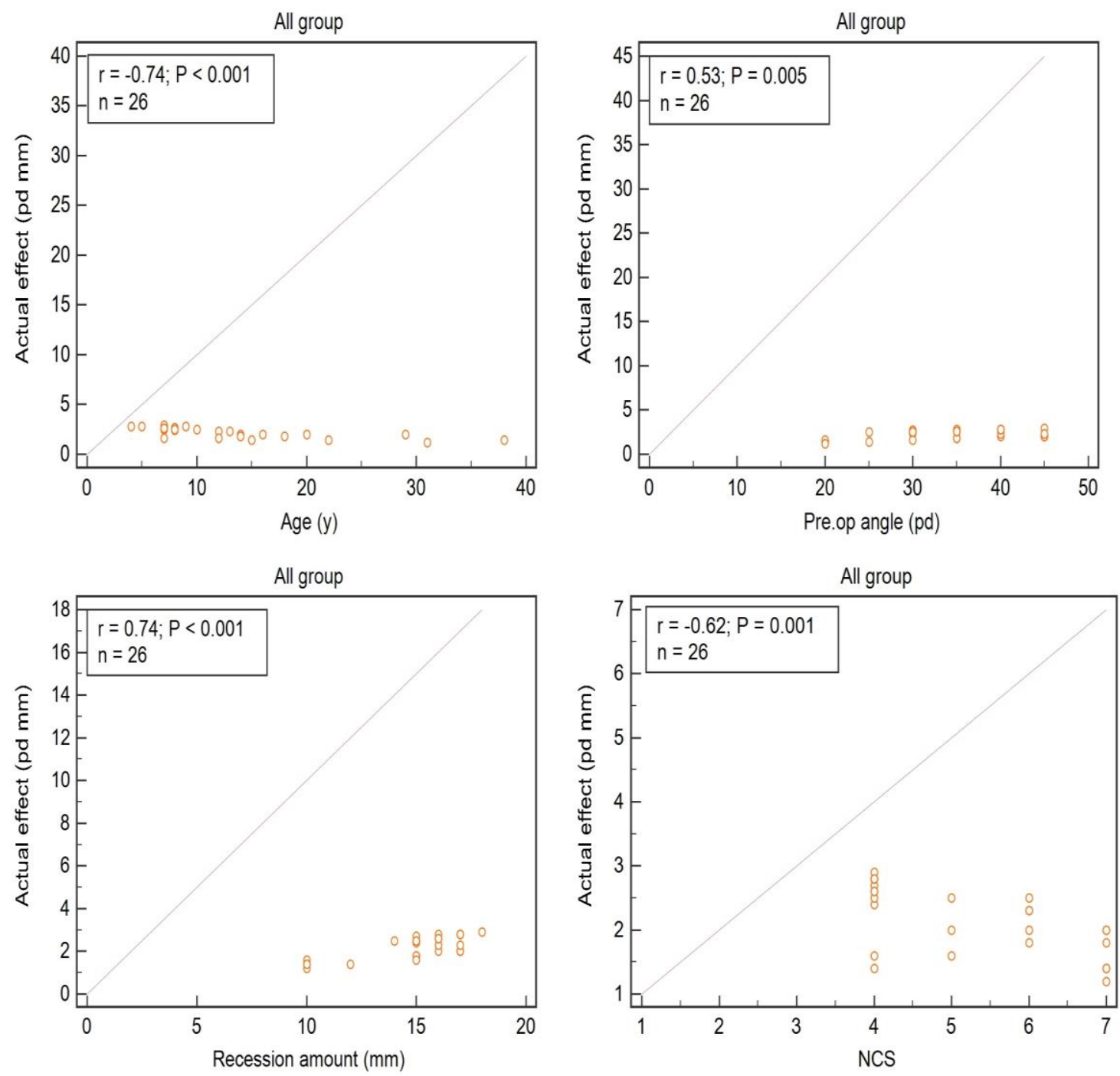

Figure 5: Pearson correlation between actual effect and other variables in the study group

\section{DISCUSSION}

Intermittent exotropia is one of the most common types of pediatric strabismus ${ }^{(14)}$. The incidence of $\mathrm{X}(\mathrm{T})$ among patients shows a female predilection ${ }^{(17)}$ However, in this study, incidence of $\mathrm{X}(\mathrm{T})$ between male and female patients was equal. In our study the aim was to analyze the effect of age at time of surgery, gender, stereoacuity and tendon width on the final surgical outcome.

The actual dose effect was calculated by finding the difference in the preoperative and postoperative angles at first day postoperative and dividing the result by the total amount of recession. The actual effect is compared to the hypothetical effect Recurrence of exotropia is common after surgical correction of intermittent exotropia ${ }^{(7)}$. Many authors adviced slight overcorrection in early postoperative period as it helps in prevention of long term recurrence ${ }^{(7,18,19) \text {. }}$
In the current study both groups showed surgical success and postoperative angle of 12 of patients (46.2\%) were within 10 PD esodeviation and 14 of patients $(53.8 \%)$ were within 10PD exodeviation, with esodeviation is common in group (1) below 10 years

Awadein et al. ${ }^{(20)}$ demonstrated that age at the time of surgery was negatively associated with the response to surgery and found the highest undercorrection was for patients older than 12 years with no overcorrection in this group. They also concluded that modifying the standard strabismus tables according to age can improve the surgical outcome in patients with intermittent exotropia. For patients 4-7 years old, the standard tables work well; whereas for patients 12 years or older, increasing the amount of recession by $1.5 \mathrm{~mm}$ significantly increased the success rate from $41 \%$ to $80 \%$.

Lee $\boldsymbol{e t} \boldsymbol{a l} .{ }^{(21)}$ reported the effectiveness of 1.5 to $2.5 \mathrm{~mm}$ augmentation of bilateral LR recession versus 
original surgery in basic-type exotropia and final success rates were higher after augmented surgery $(68.2 \%$ vs 43.9\%). Arda et al. ${ }^{(22)}$ increased the amount of bilateral LR recession to the amount needed to correct a preoperative angle that was 5 PD larger than the real angle, and the success rate was $89 \%$.

Song and Paik ${ }^{(23)}$ found that there are no significant differences at postoperative 24 months between symmetric bilateral recession and asymmetric bilateral recession in intermittent exotropia having a fixing and a deviating eye.

Lim et al. ${ }^{(\mathbf{1 3})}$ report Surgical success rate about $72.6 \%$.Other studies have reported a success rate of $41-$ $83 \%$ for BLR in early intermittent exotropia ${ }^{(24) .}$ Ruttum with his colleaques ${ }^{(25)}$ in short-term studies with 6 months follow-up havereported surgical success rates of approximately $63 \%-80 \%$. Where as studies with 5 years and above follow-up have shown a32.8\% -58\%. (26)

Lee-min et al. ${ }^{(27)}$ found success rate at one-year follow-up was $68 \%$ then success rate decreased with the length of follow-up, and their final study success rate at five-year follow-up (41\%). However, direct comparison of success rate is difficult because patient populations, follow-up periods, surgical procedures, and definition of success of surgery differ among studies.

In the presenting study the preoperative angle of deviation was not factor for a success either following unilateral or bilateral rectus recession

Lim et $\boldsymbol{a l} .{ }^{(12)}$ found that the quantity of preoperative distance deviation was not predictive of successful alignment following bilateral rectus recession which also was similar to the finding of Richard and Parks. ${ }^{(28)}$ On the other hand, Gezer et al.$^{(29)}$ reported that the preoperative angle of deviation is involved in postoperative recurrence. Lee-min et al. ${ }^{(27)}$ reported that the success group had smaller pre-operative angle of deviation for distance in comparison to the failure group.This finding also concurred with Lee $\boldsymbol{e t}$ al. ${ }^{(30)}$

In the presenting study, SE refractive error was not affecting the surgical outcome and this coincides with Lim et al. ${ }^{(13)}$ and Koklanis ${ }^{(31)}$, however Gezer et $\boldsymbol{a l}{ }^{(29)}$ found that refractive error was proved to be a significant factor influencing a favorable outcome in patients with surgically treated exotropia. Although refractive error was not associated with recurrence of exotropia in the current study, refractive error should be corrected in patients with exotropia.

In the current study the tendon width was varying from 8-9.5 mm. There is correlation between age of patients and tendon width, where we found in most children ( $\leq 10$ years of old) tendon width varying from 8 to $9 \mathrm{~mm}$, but tendon width in adult varing from 9 to 9.5 mm. In a study conducted by Yun and $\mathbf{K i m}^{(15)}$, they found tendon widths for patients under 5 years were narrower than older patients and they suggested modifying the degree of surgery according to the tendon width.

Lee et $\boldsymbol{a l} \boldsymbol{.}^{(32)}$ previously found that the tendon width of the LR muscle was significantly related to the surgical effect of LR recession when the amount of preoperative deviation was less than $25 \mathrm{PD}$, and suggested that the tendon width of the LR muscle was a useful indicator of the effect of recession surgery in patients with $\mathrm{X}(\mathrm{T})$. Kim and Choi ${ }^{(33)}$ demonstrated that the effects of unilateral recession were larger in cases in which the tendon width of the LR muscle was decreased, and the mean effect per millimeter was 3.6, 3.0, and 2.8 PD when ranges of tendon width were $6.5-7.5 \mathrm{~mm}, 8$ $8.5 \mathrm{~mm}$, and $9-9.5 \mathrm{~mm}$, respectively.

In the presenting study postoperative exodeviation angle of subjects in group 2 ranged from 4 to 10PD. Lekskul et al. ${ }^{(34)}$ found surgical management of adult $\mathrm{X}(\mathrm{T})$ by slightly intended undercorrection showed promising outcomes. They demonstrated that 197 patients $(84.19 \%)$ had successful surgical alignment, resulting in postoperative exodeviation $<10 \mathrm{PD}$. Only 12 patients $(5.12 \%)$ had postoperative exodeviation $>15 \mathrm{PD}$, requiring reoperation. In the current study the five patients with $\mathrm{X}(\mathrm{T}) \leq 25 \mathrm{PD}$ who underwent unilateral lateral rectus recession had good results. Dunlap and Gaffiney $^{(35)}$ reported that ULR as a treatment was inadequate, except in cases of small-angle exotropia (10 to $15 \mathrm{PD}$ ). The limbal insertion distance as one of the factors which influenced the results of surgery related to an equator of the globe. That we didn't measure in the presenting study. Lee et $\boldsymbol{a l}^{\left({ }^{(14)}\right.}$ found that in both unilateral and bilateral LR recession, the LID was positively correlated, where they found that the doseresponse effect was larger than expected in patients with longer limbal insertion distance of LR muscle. So, they recommended under-correction in patients with a LID of the LR muscle that is $>6.0 \mathrm{~mm}$.

\section{CONCLUSION}

Many factors can affect the surgical outcome of intermittent exotropia. Younger age, smaller preoperative angle, smaller tendon muscle width, early postoperative small angle esotropia were associated with a higher surgical success. This study has limitations which are the small number of cases and the relatively short follow-up period.

\section{REFERENCES}

1. Nusz KJ, Mohney BG and Diehl NN (2006): The course of intermittent exotropia in a population-based cohort. Ophthalmology, 113(7):1154-8. 
2. Song DS, Chen ZJ and Qian J (2018 ): Comparison of bilateral/unilateral lateral rectus recession and unilateral recession-resection for intermittent exotropia: a Metaanalysis. Int J Ophthalmol., 11(12):1984-1993.

3. Yulek F, Velez FG, Isenberg SJ et al. (2017): Binocular summation and control of intermittent exotropia. Strabismus, 25(2): 81-86.

4. Hatt SR and Gnanaraj L (2013): Interventions for intermittent exotropia. Cochrane Database Syst Rev., (5):CD003737.

5. Min EJ, Lee MK and Park BI (2001): A clinical study on strabismus in children. J Korean Ophthalmol Soc., 32:379388.

6. Lee JY, Ko SJ and Baek SU (2014): Survival analysis following early surgical success in intermittent exotropia surgery. Int J ophthalmol., 7(3):528-33.

7. Tibrewal S, Singh N, Bhuiyan MI et al. (2017): Factors affecting residual exotropia after two muscle surgery for intermittent exotropia. Int J Ophthalmol., 10(7):11201125.

8. Bae SH, Lee YB, Rhiu S et al. (2018): Early postoperative changes of motor alignment after surgery for intermittent exotropia. Graefe's Archive for Clinical and Experimental Ophthalmology, 256:1005-10.

9. Von Noorden GK and Campos EC (2002): Binocular vision and ocular motility. $6^{\text {th }}$ ed. St. Louis: Mosby.

10. Raab EL and Parks MM (1969): Recession of the lateral recti: early and late postoperative alignment. Arch Ophthalmol., 82:203-208.

11. Scott WE, Keech $R$ and Mash AJ (1981): The postoperative results and stability of exodeviations. Arch Ophthalmol., 99:1814-18.

12. McNeer KW (1987): Observations on the surgical correction of childhood intermittent exotropia. Am Orthopt J., 37:135-50.

13.Lim SH, Hwang BS and Kim MM (2012): Prognostic factors for recurrence after bilateral rectus recession procedure in patients with intermittent exotropia. Eye, 26: 846-52.

14. Lee JY, Lee EJ, Park KA et al. (2016): Correlation between the limbus-insertion distance of the lateral rectus muscle and lateral rectus recession surgery in intermittent exotropia. PLoS One, 27; 11(7):1-9.

15. Yun CM and Kim SH (2011): The tendon width of lateral rectus muscle in predicting the effect of recession: is it just age-related artifact? Eye, 25:1356-59.

16.Parks MM and Mitchell P(1988): Concomitant exodeviations in: Duane TD, (ed.) Clinical Ophthalmology JB Lippincott: Philadelphia.

17. Nusz KJ, Mohney BG and Diehl NN (2005 ): Female predominance in intermittent exotropia. Am J Ophthalmol., 140(3): 546-7.

18. McNeer KW (1987): Observations on the surgical overcorrection of childhood intermittent exotropia. Am Orthop J., 37:135-150.
19.Souza-Dias C and Uesugui CF (1993): Post-operative evolution of the planned initial overcorrection in intermittent exotropia: 61 cases. Binocul Vis Eye Muscle Surg Q., 1003:141-148.

20.A Awadein, R M Eltanamly and M Elshazly (2014): Intermitten exotropia: relation between age and surgical outcome: a change-point analysis. Eye (Lond), 28(5): 587593.

21.Lee SY, Hyun Kim J and Thacker NM (2007): Augmented bilateral lateral rectus recessions in basic intermittent exotropia. J AAPOS., 11(3):266-8.

22. Arda H, Ataly HT and Orge FH (2014): Augmented surgical amounts for intermittent exotropia to prevent recurrence. Indian J Ophthalmol., 62(11):1056-59.

23.Song HJ and Paik HJ (2010): Augmented asymmetric lateral rectu recession in intermittent exotropia with fixing eye. J Korean Ophthalmol Soc., 51(7): 992-98.

24. Chia A, Seenyen $L$ and Long QB (2006): Surgical experiences with two-muscle surgery for the treatment of intermittent exotropia. J AAPOS., 10: 206-11.

25. Ruttum MS (1997): Initial versus subsequent postoperative motor alignment in intermittent exotropia. JAAPOS., 1(2):88-91.

26. Maruo $T$, Kubota $N$ and Sakaue $T$ et al. (2001): Intermittent exotropia surgery in children: long term outcome regarding changes in binocular alignment. A study of 666 cases.binocul.vis.strabismus, 16(4):265-270.

27.Lee-min FC, Gesite-deleon BU and Quah BL (2016): Post-operative strabismus control and motor alignment for basic intermittent exotropia. Int J ophthalmol., 9(7):101115.

28. Richard JM and Parks MM (1983): Intermittent exotropia. Surgical results in different age groups. Ophthalmology, 90:1172-77.

29. Gezer A, Sezen F, Nasri N et al. (2004): Factors influencing the outcome of strabismus surgery in patients with exotropia. J AAPOS., 8:56-60.

30.Lee BJ, Kim SJ and Yu YS (2014): Factors associated with the angle of exodeviation in patients with recurrent exotropia. Br J ophthalmol., 98(10):1414-19.

31.Koklanis $K$ and Georgievski $Z$ (2009): Recurrence of intermittent exotropia: factors associated with surgical outcomes. Strabismus, 17:37-40.

32. Lee $H$ and Kim SH (2009): Bilateral lateral rectus recession considering the tendon width in intermittent exotropia. Eye (Lond), 23:1808-11.

33. Kim SH and Choi YJ (2006): Effects of unilateral lateral rectus recession according to the tendon width in intermittent exotropia. Eye (Lond), 20:785-88.

34.Lekskul A, Supakitvilekarn $T$ and Padungkiatsagul T(2018): Outcomes of undercorrection in surgical management and binocular vision gained of adult intermittent exotropia. Clinical Ophthalmology, 12:176367.

35.Dunlap EA and Gaffiney RB (1963): Surgical treatment of intermittent exotropia. Am Orthopt J., 19:20-33. 